\title{
O Design Gráfico como Diferencial Competitivo
}

\author{
Graphic Design like as Competitive Differential \\ COSTA, Jaime; Mestre; Universidade Estadual de Maringá \\ jaime.oliveira.costa@gmail.com
}

CALDAS, Jéssica; Graduada; Instituto Adventista Paranaense

Jessica caldas@hotmail.com

\section{Resumo}

Esta pesquisa tem por objetivo analisar quais são os modelos de design gráfico que estão sendo utilizados na estruturação das capas de livros e quais podem ser aplicados como fonte de vantagem competitiva no desenvolvimento de produtos, com base nas abordagens do conceito de cultura de consumo. A pesquisa é qualitativa, em que através da revisão bibliográfica e validação de profissionais na área de design, pode-se encontrar uma classificação sugestiva para os modelos de capa e assim, analisar através da coleta dos livros mais vendidos em 2013/2014, o que está sendo utilizado no mercado.

Palavras Chave: design gráfico; capa de livro; vantagem competitiva.

\section{Abstract}

This research aims to analyze which graphic design models are being used in the design of cover books and which can be applied as a source of competitive advantage in the development of products based on the approaches of the concept of consumer culture. This research is qualitative through the bibliographic revision and validation of graphic design professionals. A suggestive classification can be found in for the cover books models to analyze through the collection of the most soldest books in 2013/2014 that are being used in the market.

Keywords: graphic design; cover book; competitive differential .

\section{Introdução}

A capa é de suma importância para os livros. Segundo Hoeltz (2001) a primeira página de um impresso é considerada a embalagem do produto. Fonseca (p. 248, 2008) assinala que "o público, cada vez mais consciente do design, prefere sempre comprar a publicação visualmente mais atrativa, mais fácil de ler e que apresente a informação de forma clara e compreensível". Assim, os aspectos de design gráfico que norteiam a capa de um livro podem ser considerados fontes de vantagem competitiva, tendo em vista a possibilidade de obtenção 
retornos significativos para a organização.

Magalhães (1981) considera que a capa assume função promocional do livro, ela tem a responsabilidade de vendê-lo, ou colaborar para esta venda. Estes aspectos estão diretamente ligados a cultura de consumo da atual sociedade capitalista. De acordo com Barbosa (2010) a cultura de consumo cresce a partir do poder de escolha e de interesses, muitas vezes influenciados pelo marketing e a propaganda. Para o autor a cultura de consumo se tornou o principal foco do mundo atual, onde as práticas, os costumes, as ideias, são determinadas e orientadas pela compra. Este foco pode definir a sociedade contemporânea como materialista, mas também, um mundo em que prevalece a liberdade de escolhas.

A cultura de consumo envolve o acesso frequente a coisas que são apresentadas como novas bem como as tendências. E esta necessidade sem limites é comum e é considerada essencial para a ordem e o crescimento socioeconômico (SLATER, 2002). Desta forma, obter sucesso no mercado implica em garantir renovações constantes e boas estratégias organizacionais. Porém, a estratégia organizacional deve ser avaliada através das perspectivas da cultura de consumo. Mintzberg (2000) afirma que esta estratégia requer não apenas a previsibilidade, mas também a estabilidade no decorrer da sua formação. Giglio (2005, p. 43) defende que a estratégia organizacional “...não precisa estar fundamentada só em necessidades do presente, mas nas expectativas (o futuro) que movem o sujeito por meses e anos".

Contudo, o presente estudo proporciona uma oportunidade para que as organizações possam interpretar o comportamento do consumidor de livros de acordo com suas preferências em relação a capa dos materiais. Em outras palavras, a proposta é sugerir um modelo de classificação de design gráfico da capa de livros e verificar o que está sendo utilizado no mercado, a fim de possibilitar a identificação da preferência dos consumidores. Neste contexto, esta pesquisa propõe responder a seguinte problemática: Como o design gráfico utilizado na capa de livros, pode ser utilizado como fonte de vantagem competitiva?

Com intuito de responder tal indagação, foi estabelecido o objetivo geral do estudo, que implica em investigar quais são os modelos de design gráfico utilizados na estruturação das capas de livros. Para tanto, foi definido os seguintes objetivos específicos: Caracterizar os modelos de design gráfico utilizados na capa dos livros e elaborar uma classificação para as mesmas, tendo em vista as abordagens do conceito de cultura de consumo; Identificar quais os tipos de design gráfico utilizados nas mídias estimulados por esta cultura.

\section{Design gráfico}

O design gráfico tem o poder de deixar os materiais mais atrativos, geralmente com objetivo de transmitir alguma informação. Segundo Simões (1976, p. 141) design é “... a arte e a ciência de aumentar a beleza e o valor dos artigos produzidos em massa...". Sampaio (1999) acredita que o design tem se tornado uma das mais importantes ferramentas de comunicação, pois é a partir dele que ocorre o primeiro contato com a empresa. O autor ainda acrescenta que este meio tem a função de trabalhar com cores, traços e formas. Porém, nem sempre é fácil organizar estes elementos para que mantenham harmonia e transmitam a informação correta.

Newark (2009) aponta que o design gráfico é a mais universal de todas as artes, que se 
encontra em todos os lugares, decorando, identificando e colocando significado ao mundo. $\mathrm{O}$ design realiza diversas funções, dentre elas, distingue e classifica as coisas, como por exemplo, a identificação de uma empresa que a diferencia das outras. Hollis (2000) afirma que o designer gráfico tem três principais funções:

- Identificar: mostrar o que é determinada coisa ou de onde ela veio, como logotipos de empresas, faixadas de hotéis, rótulos em embalagens, entre outros;

- Informar e instruir: indicar direções, posições e escalas, poder ser visto em mapas, diagramas e sinais de direção;

- Apresentar e promover: divulgar mensagens, a fim de prender a atenção mostrar o produto ou serviço oferecido, como pôsteres, anúncios publicitários, folders...

Contudo, organizar estes elementos para que alcancem o objetivo almejado, é tarefa não muito simples e depende de profissionais capacitados e que tenham prática e olhar amplo para o mundo. O tópico a seguir demonstra alguns tipos de classificações de design gráfico que norteiam a proposta sugerida por este estudo.

\section{O design gráfico e suas classificações}

Existem diversos tipos de design gráfico. Alguns autores destacam determinados estilos que são mais utilizados. Fuentes (2006) aponta que o design gráfico trabalha com quatro tipos de imagens:

1) Esquemas: Utilizados para exemplificar ou mostrar sistemas, procedimentos ou desenvolvimentos que por suas características são difíceis de serem visualizadas. São apresentadas através de organogramas, cronogramas, redes, histogramas, entre outros, que tem o propósito de representar estados, estruturas, relações, evoluções...

a) Infogramas: São esquemas bastante utilizados na imprensa diária, na televisão e em livros didáticos. Costumam demonstrar acontecimentos que transcorram em um determinado período. São exemplos: um acidente automobilístico, um lance de futebol, ações militares...

b) Pictogramas: Figuras representativas, que buscam transmitir informações complexas rapidamente.

2) Ilustração: Procura mostrar acontecimentos, personagens ou cenas, através de uma préfotografia. Em algumas situações, é a única forma de representar fatos, processos e interpretações pessoais que não são visíveis. É importante lembrar que a ilustração por si só, não é design gráfico, é necessário conter outros elementos para torná-la um design.

3) Fotografia: É considerada uma ferramenta de fotogravura e um veículo representante de outras expressões. É utilizada em a partir de dois pontos fundamentais:

a) Registro fotográfico: Fotografia de objetos, situações ou personagens, de modo informativo ou científico. Procura transmitir a informação de modo detalhado.

b) Ilustração fotográfica: É a junção de uma ideia com a expressão gráfica, que tem a necessidade de transmitir literalmente o conceito. Ou seja, é a utilização dos componentes gráficos das imagens adquiridas por meio de técnicas fotográficas, próprias para aplicação das 
informações e do design gráfico.

4) Digitalização direta: É quando ocorre a digitalização direta de vários modelos de materiais, sem antes passar por um processo óptico.

Ainda nesta mesma linha de considerações, vale enfatizar o papel da tipografia, que pode ser considerado outro tipo de design gráfico. As palavras podem ser transformadas em figuras e isto "significa definir uma relação simples entre a forma intrínseca das letras e alguma outra ideia visual" (SAMARA, 2011, p. 97). Ou seja, a tipografia consiste em usar os tipos, ou as letras bem como suas fontes, a fim de transmitir informação de forma simbólica e visual. Fonseca (2008) acrescenta que as fontes tipográficas podem ser classificadas de acordo com os estilos e processo de evolução.

Um dos principais tipos de design se refere ao minimalismo. Segundo Carrion (2008), o conceito do design minimalista se resume na expressão do arquiteto alemão Ludwig Mies Van der Rohe, a qual afirma que "menos é mais". Este modelo não se refere simplesmente ao "pouco", mas sim, em maximizar a essência do que realmente tem importância, o design deve manter o trabalho limpo, "livre de qualquer desvio de atenção por meio de excesso de estética" (CARRION, 2008, p. 152). O autor identifica que minimalismo é considerado um movimento que marcou a base da criatividade do século XX, e não está presente somente no design gráfico, mas também, na arquitetura, na música, no raciocínio lógico, na web e na informática em geral.

Pode-se destacar ainda como modelo de design, a imagem vetorial. Martins (2005, p. 21) considera que "ao contrário das imagens mapeadas por bits, as imagens vetoriais, criadas em softwares de desenho, são compostas de linhas, ângulos e formas geométricas predefinidas por comandos no computador e por cálculos matemáticos". O autor aponta que um vetor pode ser reorganizado quantas vezes forem precisas e é independente em relação à resolução, ou seja, a imagem pode ser ampliada para qualquer tamanho que não sofrerá perda de detalhes na visualização. A ilustração vetorial é mais adequada para desenhos de marcas, símbolos e logotipos, pois compõem desde a impressão em papéis até letreiros e banners maiores.

Contudo, diversos estilos de design gráfico foram encontrados, tendo em vista a sugestão de diversos autores. A classificação geral destes modelos é sugerida no decorrer deste estudo.

\section{O design gráfico nas capas de livros}

A capa é de suma importância para os livros. Segundo Hoeltz (2001) a primeira página de um impresso é considerada a embalagem do produto, sendo assim, é necessário que apresente componentes de identificação atrativos com intuito de que o leitor veja e a diferencie, reconhecendo assim, diante dos outros produtos. Magalhães (1981) considera que a capa assume função promocional do livro, ela tem a responsabilidade de vendê-lo, ou colaborar para esta venda. Isto é, a capa pode servir como componente que fornece suporte para a venda, não algo que irá garantir o consumo.

O leitor possui conhecimentos básicos de design, é exigente e crítico em suas escolhas. Fonseca (2008, p. 248) assinala que "o público, cada vez mais consciente do design, prefere sempre comprar a publicação visualmente mais atrativa, mais fácil de ler e que apresente a informação de forma clara e compreensível". Ou seja, além do consumidor possuir certa noção 
de design gráfico, ainda procura materiais impressos que facilitem a leitura de forma fluente e clara. Samara (2011, p. 123) afirma que o design das capas de livros exige algo semelhante a um cartaz, de forma que possa "atrair os leitores em ambientes de vendas abarrotados e comunicar o conteúdo da obra de forma visceral".

O design gráfico de um material impresso, bem como o espaço ocupado e a sua disposição no mesmo, só apresenta o resultado esperado se conseguir seguir além dos níveis de planejamento, o editorial, comercial e gráfico, também a utilização perpétua de aspectos que garantem uma identidade definida na produção final (HOELTZ, 2001). Ou seja, não basta apenas investir em boa produção gráfica de design simplesmente na capa, é necessário que o material esteja em plena conversação visual por completo, tanto na parte externa, como interna. Isto pode transmitir melhor qualidade do produto e segurança ao leitor.

\section{Caracterização da pesquisa}

Este tópico apresenta os métodos utilizados na elaboração deste estudo, bem como a caracterização da pesquisa. Quanto à natureza, caracteriza-se como básica. De acordo com Marconi e Lakatos (2010) é a partir deste modelo de estudo que o pesquisador busca, através dos procedimentos científicos, maximizar o conhecimento da teoria.

Em relação à forma de abordagem, é determinada como pesquisa qualitativa com aporte quantitativo. Isto deve-se ao fato de que fora realizado busca teórica e documental, os quais são mensurados a partir da coleta de capas de livros. Os documentos são utilizados como fonte de coleta de dados que podem ser escritos ou não. Estes fazem parte das fontes primárias e podem ser realizadas no momento em que o fenômeno ocorre ou após (MARKONI e LAKATOS, 2010).

Tratando dos objetivos, esta pesquisa é caracterizada como descritiva e explicativa. A pesquisa apresenta levantamento experimental, que, conforme Gil (2002), consiste em estabelecer um objeto de estudo, definir as variáveis que podem influenciar e determinar os modos de controle e análises dos resultados que a variável apresenta no objeto.

\section{Procedimentos metodológicos}

A presente pesquisa foi realizada a partir de duas etapas, sendo que a primeira é considerada qualitativa, a partir da revisão bibliográfica e a segunda quantitativa, por meio da coleta e mensuração de materiais.

O método aplicado exigiu a elaboração de instrumentos de coleta para a medição dos construtos envolvidos na pesquisa, ou seja, a identificação dos modelos de design gráfico utilizado nas capas de livros, bem como a sua classificação de forma mensurável. Sendo assim, foi realizado, a partir do referencial teórico, a caracterização destes modelos e diretamente relacionados às dimensões pesquisadas.

Para tanto, foi contatado quinze doutores na área de design gráfico e artes visuais, a fim 
de validar o material coletado. Estes entrevistados foram selecionados a partir da Plataforma Lattes, onde foram analisados seus devidos currículos de acordo com experiências e formações na área. O contato foi feito primeiramente por telefone, com intuito de verificar a disponibilidade dos profissionais para realizarem a validação. Após o aceite, o material foi enviado por meio eletrônico, via e-mail, onde cada respondente teve a liberdade de fazer seus apontamentos e sugestões.

Após as observações e validação dos profissionais, foram realizados os devidos ajustes sugeridos na tabela de classificação das capas. Em seguida, foram coletadas 315 capas de livros, as quais foram analisadas individualmente de acordo com suas estruturações e características de design gráfico de cada material.

O critério para a coleta dos livros foi determinado por área de conteúdo dos materiais, baseado na classificação da livraria Saraiva, que representa um total de 21 categorias: administração, artes, ciências biológicas, ciências humanas, cursos e idiomas, didáticos, espiritualismo, geografia e história, literatura infanto-juvenil, medicina, religião, agropecuária, autoajuda, ciências exatas, contabilidade, dicionários e manuais, direito, gastronomia, literatura estrangeira, literatura nacional e psicologia.

Dentre estas categorias identificadas, foram coletadas as capas dos 15 livros mais vendidos de cada área nos anos de 2013/2014. Foi estipulado este período apenas como referência para identificação dos modelos de capas utilizadas no mercado, o que não compromete o resultado principal da pesquisa, que refere-se a análise sobre o design gráfico utilizado nas capas. Desta forma a pesquisa pode ser considerada atemporal. O conteúdo foi organizado e orientado em função dos objetivos perseguidos. Contudo, a análise dos dados foi feita em duas etapas de acordo com o método da pesquisa. A primeira, efetuada a partir da análise de conteúdo do referencial teórico, em que foram classificadas as capas de livros a partir dos modelos encontrados, respeitando as definições de Fuentes (2006) e Samara (2011). E a segunda através da tabulação dos dados, identificando os modelos de capas de livros mais utilizados no mercado.

\section{Resultados}

Na primeira etapa foi elaborada a classificação do design das capas dos livros a partir do referencial teórico. Foram identificados dez modelos distintos, os quais podem ser exemplificados e classificados resumidamente da seguinte forma: 
Figura 1 - Classificação Inicial dos Modelos de Design Gráfico dos Livros

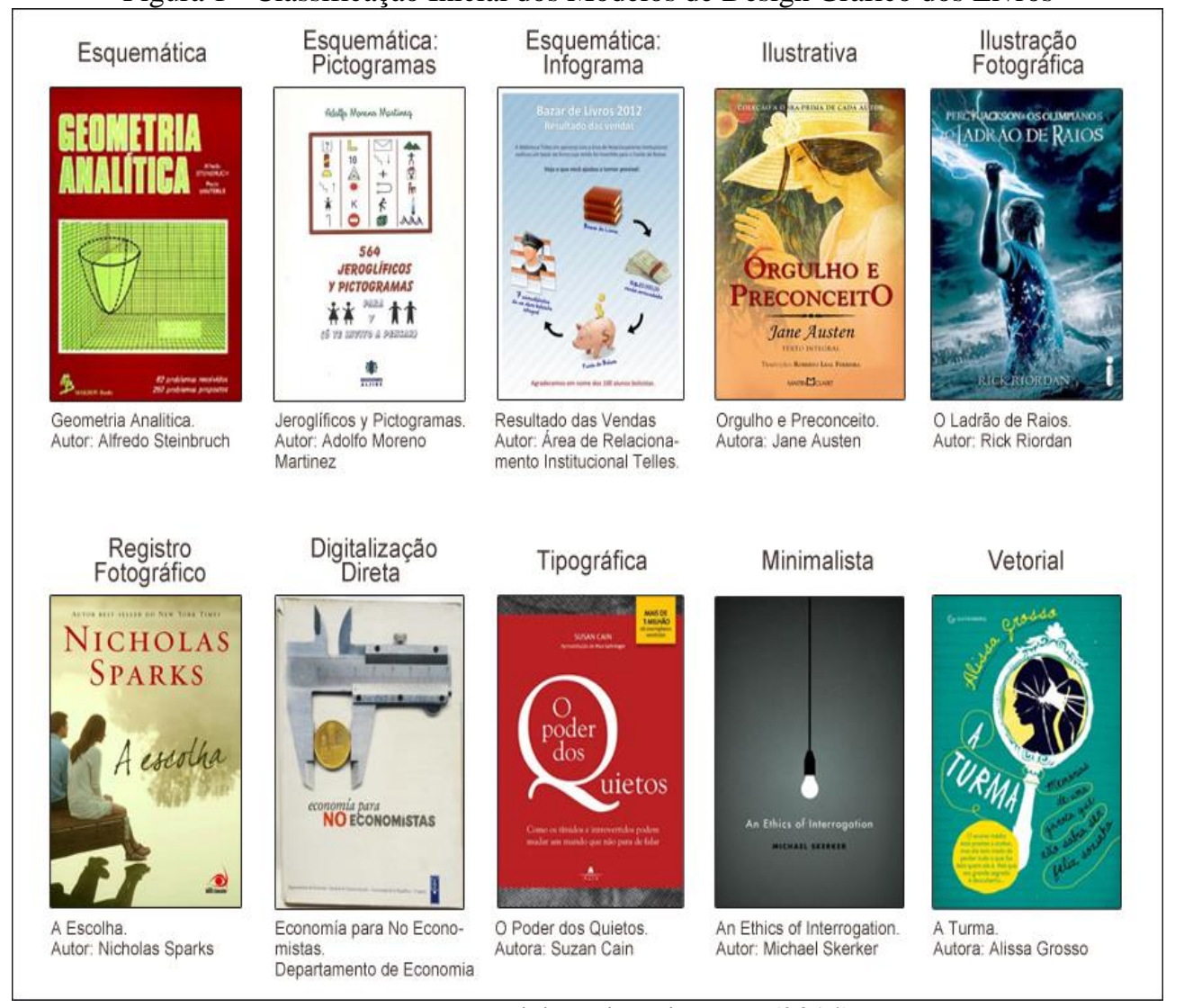

Fonte: Elaborado pelo autor (2014).

Para validar a classificação encontrada, foi contatado quinze profissionais na área de design gráfico com ênfase em artes visuais. Destes, apenas três prontamente avaliaram o material, o que já se torna bem representativo para garantir a confiabilidade da pesquisa.

De modo geral, todos os respondentes acreditaram na classificação elaborada, porém, cada um fez seus apontamentos sugerindo ajustes e assinalando limitações do material, os quais foram considerados na pesquisa.

De acordo com Profissional 1, "a classificação está bem autoral, mas não está errada e pode ser bem válida". Por ser uma classificação criada pelo pesquisador, o profissional sugeriu deixar claro este aspecto, pois se "...formos falar de técnicas visuais propriamente ditas, seria necessária uma formação na área...”. Acrescenta ainda, que o material coletado pode ser utilizado em futuras pesquisas, pois apresenta de forma simples e clara os modelos e estilos de design existentes, que não se fixa somente nas capas de livros, mas que também pode ser encontrado em outros canais.

O Profissional 2 sugeriu ainda que reduzisse as classificações, “...pois no desenho esquemático podemos incluir os pictogramas, por exemplo...". Pelo fato de ser muito extensa e alguns modelos se encaixarem em outros, foi proposto uma nova classificação com diferentes termos de uso. Sendo assim, onde inicialmente obtínhamos dez modelos, agora encontramos seis. As alterações realizadas foram as seguintes: Esquemáticas e pictogramas são consideradas representações esquemáticas; ilustrativa e registro fotográfico são representações realísticas; 
ilustração fotográfica, digitalização direta e minimalista são técnicas fotográficas. Os demais modelos permaneceram os mesmos, porém renomeados, como a técnica infográfica, técnica tipográfica e representação vetorial. Contudo, a nova classificação ajustada, conforme sugerida, ficou da seguinte forma:

Quadro 1 - Classificação dos Modelos de Design Gráfico Ajustada

\begin{tabular}{|l|l|}
\hline \multicolumn{1}{|c|}{ Classificação Inicial } & \multicolumn{1}{c|}{ Classificação Ajustada } \\
\hline Esquemática & Representação Esquemática \\
\hline Infogramas & Técnica Infográfica \\
\hline Pictogramas & Representação Esquemática \\
\hline Ilustrativa & Representação Realística \\
\hline Registro Fotográfico & Representação Realística \\
\hline Ilustração Fotográfica & Técnica Fotográfica \\
\hline Digitalização Direta & Técnica Fotográfica \\
\hline Tipográfica & Técnica Tipográfica \\
\hline Minimalista & Técnica Fotográfica \\
\hline Vetorial & Representação Vetorial \\
\hline
\end{tabular}

Fonte: Elaborado pelo autor (2014).

\section{Considerações finais}

Contudo, após o desenvolvimento da pesquisa, alguns pontos merecem destaque. Tratando do primeiro objetivo específico que se refere à caracterização dos modelos de design gráfico utilizados nas capas de livros e elaboração de uma classificação para as mesmas, a luz das abordagens do conceito de cultura e consumo; pode-se verificar que a pesquisa atingiu a finalidade estabelecida. A partir das referências bibliográficas, em que merecem destaques os autores Fuentes (2006), Samara (2011), Carrion (2008), Martins (2005) e também da validação e apontamentos dos profissionais, foi possível sugerir uma classificação do design gráfico utilizado nas capas dos livros.

A classificação realizada contou com os seguintes modelos de design gráfico: representação esquemática, técnica infográfica, representação realística, técnica fotográfica, técnica tipográfica e representação vetorial. Porém, algumas considerações realizadas pelos profissionais não podem ser ignoradas a despeito desta classificação. De acordo com os profissionais, é importante dar ênfase que esta estruturação foi elaborada pelo autor, a qual não possui formação na área, e que se fosse realizar uma análise mais profunda das técnicas visuais propriamente ditas, seria necessária tê-la. Entretanto, o profissional acrescenta ainda que a classificação apresenta de forma simples e clara os modelos de design existente e que pode ser aplicada na análise em outros canais.

A partir da classificação elaborada e da coleta dos 315 livros mais vendidos em 2013/2014, foi possível verificar que o modelo de design gráfico denominado representação realística é utilizado na maior parte das capas dos livros mais vendidos, este grupo representa $45,08 \%$ da coleta, em seguida, também com destaque a técnica tipográfica, que equivale a $24,76 \%$ das capas. É importante mencionar que a editora Saraiva foi a que publicou a maior parte destes materiais, demonstrando $31 \%$ das vendas. 
Porém, ao analisar cada área de literatura, que são 21, conforme classificação da livraria Saraiva, observa-se que alguns modelos de design são referências em determinadas categorias, é o caso das áreas de agropecuária, artes, autoajuda, ciências biológicas, didáticos, espiritualidade, gastronomia, geografia e história, infanto-juvenil, literatura estrangeira, literatura nacional e medicina, onde design gráfico mais utilizado é a representação realística. Já nas áreas de administração, ciências exatas, contabilidade, cursos e idiomas, dicionários e manuais de conversação, direito e psicologia, a técnica tipográfica se destaca. Somente nas capas dos livros da área de ciências humanas e sociais a representação vetorial é mais encontrada. Entretanto, a outra metade dos modelos que são a técnica infográfica, a representação esquemática e a técnica fotográfica, não aparece como referência de design em nenhuma das áreas. Sendo assim, o segundo objetivo que se trata da identificação dos modelos de design gráficos mais utilizados nas mídias estimuladas pela cultura de consumo, foi atendido conforme proposto pela pesquisa.

Contudo, foi possível sugerir um modelo de classificação da capa de livros que pode direcionar futuras pesquisas a investigar a preferência dos consumidores de forma objetiva e mensurável. Assim, torna-se possível sugerir aos designers gráficos aqueles modelos que são preferência do público, o que pode gerar vantagem competitiva para as organizações. No entanto, é importante salientar que a capa pode servir como componente que fornece suporte para a venda, não algo que irá garantir o consumo.

\section{Referências}

BARBOSA, Lívia. Sociedade de consumo. 3. ed. - Rio fr Janeiro: Zahar, 2010.

CARRION, Wellington. Design para Webdesigners. Rio de Janeiro : Brasport, 2008.

FONSECA, Joaquim da. Tipografia e design gráfico: design e produção gráfica de impressos de livros. Porto Alegre: Bookman, 2008.

FUENTES, Rodolfo. A prática do design gráfico: uma metodologia criativa. São Paulo: Edições Rosari, 2006.

GIGLIO, Ernesto Michelangelo. O comportamento do consumidor. 3. Ed. São Paulo: Pioneira Thomson Learning, 2005.

GIL, Antônio Carlos. Como elaborar projetos de pesquisa. 4 ed. São Paulo: Atlas, 2002.

HOELTZ, Mirela. Design Gráfico-dos espelhos às janelas de papel. In: Congresso Brasileiro de Ciências da Comunicação, 2001. 
HOLLIS, Richard. Design gráfico: uma história concisa. 1 ed. São Paulo: Martins Fontes, 2000.

MAGALHÃES, Aluisio. Editoração hoje. $2^{\mathrm{a}}$ ed. Rio de Janeiro: Ed. da Fundação Getulio Vargas, 1981.

MARCONI, Marina de Andrade; LAKATOS, Eva Maria. Fundamentos de metodologia científica. In: Fundamentos de metodologia científica. Atlas, 2010.

MARTINS, Nelson. A imagem digital na editoração: manipulação, conversão e fechamento de arquivos. Rio de Janeiro: Senac Nacional, 2005.

MINTZBERG, Henry; AHLSTRAND, Bruce; LAMPEL, Joseph. Safári da estratégia. Bookman, 2009.

NEWARK, Quentin. O que é design gráfico? 1. ed. Porto Alegre: Bookman, 2009.

SAMARA, Timothy. Guia de tipografia: manual prático para o uso de tipos no design gráfico. Porto Alegre: Bookman, 2011.

SAMPAIO, Cláudio Hoffmann et al. Fatores visuais de design e sua influência nos valores de compra do consumidor. Revista de administração de empresas. Vol. 49, n. 4,(out./dez. 2009), p. 373-386, 2009.

SIMÕES, J.; BISPO, Renato. Design Inclusivo: acessibilidade e usabilidade em produtos, serviços e ambientes. Manual de apoio às acções de formação do projecto Design InclusivoIniciativa EQUAL. 1 ${ }^{a}$ edição da Divisão de Formação da Câmara Municipal de Lisboa-2003, 2006.

SLATER, Don. Cultura do consumo. 1 ed. São Paulo: Nobel, 2002. 